\title{
Telaah Alat Musik Tradisional Etnik Mbojo sebagai Media Pembelajaran Fisika
}

\author{
Khairil Anwar. ${ }^{1)}$, Sparisoma Viridii ${ }^{2)}$, Dadi Rusdiana. ${ }^{3)}$, dan Ida Kaniawati ${ }^{4)}$ \\ ${ }^{1}$ Program Studi S3 Pendidikan IPA, \\ Program Pascasarjana Ilmu Pengetahuan Alam, UPI \\ 3,4 Departemen Pendidikan Fisika, FMIPA Universitas Pendidikan Indonesia \\ Jl. Dr. Setiabudhi, No. 229 Bandung, Indonesia, 40154 \\ ${ }^{2}$ Nuclear Physics and Biophysis Research Division \\ Institut Teknologi Bandung, \\ Jl. Ganesha no. 10 Bandung, Indonesia, 40132 \\ ${ }^{1)}$ hairil_physic@yahoo.com (corresponding author) \\ 2) dudung@fi.itb.ac.id
}

\begin{abstract}
Abstrak
Salah satu alat musik tradisional etnik Mbojo-NTB (Nusa Tenggara Barat) adalah "Gambo". Masyarakat Mbojo memanfaatkan alat musik tradisional ini sebagai media hiburan, upacara adat, medis, serta edukasi agama dan moral, namun penggunaan sebagai media pembelajaran sains (fisika) belum pernah dilakukan karena belum adanya informasi sebagai referensi untuk dijadikan bahan pembelajaran fisika. Oleh karena itu, dilakukan telaah dan rancangan teknik eksperimen yang tepat melalui media alat musik gambo berbantuan ICT (Information Comunication and Technology) sebagai bahan pembelajaran fisika pada konsep gelombang dan bunyi. Tujuannya adalah 1). menyebutkan nama bagian-bagian gambo secara kualitatif dan kuantitaif dan makna filosofis, 2). menentukan frekuensi harmonik dan deretan nada pada pelarasan serta membandingkanya dengan skala nada modern, 3). menentukan pola hubungan perubahan panjang dawai getar terhadap frekuensi dasar, kelajuan perambatan bunyi dalam dawai, intensitas dan durasi rata-rata bunyi nada, serta gaya tegangan masing-masing dawai dalam suatu pelarasan, 4). menentukan deretan tangga nada yang dominan dimainkan dalam alat musik gambo, 5). Memvisualisasikan sinyal bunyi (waveform) yang dihasilkan dawai gambo. Pengumpulan data melalui studi pustaka, observasi, dan wawancara, serta studi kasus pada fenomena bunyi gambo (eksperimen). Penentuan karakteristik bunyi gambo (seperti timbre, frekuensi harmonik, frekuensi nada pelarasan, dan durasi) digunakan software cool edit pro/Adobe audition), sedangkan intensitas bunyi nada menggunakan applikasi smartphone android. Kelajuan perambatan bunyi pada masing-masing dawai gambo dianalisis berdasarkan fitting grafik. Datadata yang diperoleh dianalisis secara deskriptif kuantitatif untuk menentukan besaran fisis yang terkait dengan karakteristik akustik gambo. Hasil penelitian menunjukkan bahwa penciptaan alat musik Gambo memiliki makna filosofis kehidupan dan edukasi moral yang terkait dengan rukun iman dan Islam. Sementara itu informasi fisis dan matematis frekuensi-frekuensi dasar setiap dawai pada pelarasan/tuning standar gambo diperoleh identik dengan susunan frekuensi nada $G_{4}, C_{4}, F_{3}$ atau dengan bunyi nada sol, do, fa (untuk nada dasar do $=C$ ) dalam skala nada musik modern, sedangkan deretan tangga nada yang lazim dimainkan dalam gambo hanya terdiri dari 4 susunan nada untuk setiap dawai dan susunan nada tersebut belum memiliki istilah dalam masyarakat Mbojo. Intensitas bunyi nada-nada yang dihasilkan gambo diperoleh rata-rata sebesar $(88,07 \pm 0,20) \mathrm{dB}$, dengan rata-rata durasi $(0,434 \pm 0,063)$ detik. Besarnya kelajuan perambatan gelombang bunyi pada masing-masing dawai gambo berturut-turut sebesar 304,20 m/s, 202,40 $\mathrm{m} / \mathrm{s}$, dan 134,40 m/s dengan ketegangan 45.60, 25.40, dan $14.30 \mathrm{~N}$. Disimpulkan bahwa pemanfaatan alat musik etnik Mbojo "Gambo" terintegrasi ICT dapat memberikan kontribusi sebagai media pembelajaran sains (fisika) yang menarik, dan membentuk karakter peserta didik.
\end{abstract}

Kata-kata kunci : Gambo, karakteristik akustik, pembelajaran sains, ICT. 


\title{
PENDAHULUAN
}

Indonesia memiliki berbagai macam adat-istiadat dan budaya yang menjadi karakteristik suatu kelompok masyarakat (etnik tertentu), namun pemahaman terhadap nilai-nilai kearifan lokal, potensi lokal, yang menyimpan nilai-nilai pedagogik dan sains semakin terkikis. Masyarakat etnik Mbojo (daerah Bima-Dompu, Provinsi Nusa Tenggara Barat/NTB) dalam kebudayaan seni musiknya memiliki alat musik taradisional, salah satunya "Gambo", yaitu alat musik petik dan dawai sebagai sumber bunyi nya[6] yang masih dikenal hanya sebagai alat seni pelengkap dalam acara-acara adat dan pemenuhan kebutuhan psikologi jiwa manusia dalam kehidupan sehari-hari, namun pengetahuan oleh generasinya semakin terkikis sebagaimana hasil field study pada 117 responden yang hanya mencapai $7 \%$ saja, sedangkan penggunaan sebagai media pembelajaran (khususnya fisika) belum pernah dilakukan.

Dalam beberapa referensi terdapat suatu informasi mengenai ukuran dan bagian-bagian gambo, namun di sisi lain dalam perkembanganya menurut Dole Mose (2015) seorang pemain, penyanyi, dan pembuat Gambo di Desa Samili Kab. Bima mengatakan bahwa untuk ukuran Gambo di seluruh daerah Mbojo belum diketahui ukuran bakunya, demikian pula referensi jenis tangga nada, laras nada baku, karakteristik fisis dan matematisnya belum pernah ditemui sepanjang penelusuran referensi yang berhasil dilakukan sehingga perlu pengkajian kembali secara ilmiah terhadap desain dan ukuran gambo serta karakteristik akustik yang tepat agar dapat menghasilkan alat musik dengan produksi bunyi yang seragam, berkualitas, dan nyaman dimainkan sebagai alat musik khas dari etnik Mbojo maupun sebagai media belajar fisika.

Sementara itu, untuk menganalisis sinyal bunyi diperlukan sarana ICT dengan fasilitas yang tepat dan memadai[20] berikut dengan teknik komputasi yang dikenal dengan FFT/Fast Fourier Transform[8]. Beberapa contoh perangkat lunak dan hardware yang dapat digunakan sebagai sistem akuisisi data yaitu sound forge (Sony Company), Adobe Audition ${ }^{\mathrm{TM}}$ ) (Steinberg Media Technologies AG, 2004), Seventh String Tuning fork, Seventh String Tuner, Frekuency Analyzer, dan Raven Lite 1.4[21], Audacity 1.3.12 dapat memvisualisasikan gelombang bunyi[12], dan Smartphone yang dapat mendukung pembelajaran dengan applikasi penganalis frekuensi bunyi yaitu yang memiliki sistem operasi (OS) berbasis android[14], namun dari semua perangkat yang dikemukakan di atas belum dikelola dan diterapkan secara familiar untuk pembelajaran fisika.

Dalam makalah ini akan dipaparkan suatu hasil kajian mengenai nilai-nilai filosofis dan edukasi dari bagian-bagian gambo untuk merancang pembelajaran sains dengan memanfaatkan alat musik tradisional yang diintegrasikan dengan applikasi teknologi smartphone dan komputer pada pokok bahasan yang berkaitan dengan konsep gelombang bunyi pada dawai yang bergetar, mengetahui bagaimana langkah-langkah operasional dalam melakukan eksperimen yang tepat untuk menentukan frekuensi dasar dan deretan tangga nada, intensitas dan durasi nada-nada yang dihasilkan gambo, dan bagaimana hubungan antara panjang dawai dengan frekuensi dasar serta penentuan kelajuan perambatan bunyi dalam dawai yang dipengaruhi oleh jenis bahan dawai dan gaya tegangannya.

\section{BUNYI PADA INSTRUMEN MUSIK}

\begin{abstract}
Alat Musik Gambo
Klasifikasi alat musik Mbojo secara umum dapat berdasarkan pada jenis alat musik dan cara memainkannya. Didasarkan pada jenis sumber bunyi terdiri dari alat musik kolom udara, alat musik berdawai, dan alat musik pelat atau membran yang bergetar, sedangkan berdasarkan pada cara memainkanya dapat dibedakan menjadi alat musik petik, pukul, ketok, gesek, dan tiup. Adapun macam-macam nama alat musik tradisional etnik Mbojo (Bima-Dompu) diantaranya: Tende-Teta-Cambo-tambu, Silu, Sarone, Genda, No (Gong), Katongga (tawa-tawa), katongga sera dan ta'a tumba, kareku kandei, Nu'a, Biola, Arubana, dan Gambo[1].

Dalam Ensiklopedia Musik Indonesia seri F-G (1985) dijelaskan bahwa alat musik kordofon jenis lud di daerah Bima dan Dompu (Suku Mbojo) Provinsi NTB (Nusa Tenggara Barat) pada umumnya lebih terkenal dengan nama gambo yang merupakan alat musik berdawai.
\end{abstract}

\section{Sumber Gelombang Bunyi}

Gelombang bunyi, lebih khususnya dikenal dengan gelombang akustik [17], dan bunyi berasal dari sebuah benda yang bergetar. Bentuk gelombang yang tidak periodik akan terdengar sebagai derau/noise[5]. Pada 
contoh bunyi alat musik, dihasilkan warna bunyi yang teratur karena bunyi yang terbentuk merupakan gelombang periodik dan telah ditetapkan nilai frekuensinya[11].

Getaran dawai merupakan sumber bunyi. Laju penjalaran gelombang $v$ pada dawai berhubungan dengan akar tegangan $F$ dan massa persatuan panjang $\mu$ [11],[18],[16]. Nada yang dihasilkan oleh dawai dapat bermacam-macam, tergantung cara memberi tumpuan pada dawai itu yang berarti mengubah ukuran panjang. Frekuensi nada dasar $f_{\mathrm{o}}$ dinyatakan oleh[16]:

$$
f_{\mathrm{o}}=\frac{v}{\lambda_{\mathrm{o}}}=\frac{v}{2 \ell}=\frac{1}{2 \ell} \sqrt{\frac{F}{\mu}}
$$

sehingga besarnya kelajuan perambatan bunyi pada dawai yang bergetar dapat dihitung dengan persamaan:

$$
v=2 \ell . f_{\mathrm{o}}
$$

dan ketegangan dawai dapat ditentukan oleh hubungan:

$$
F=v^{2} \cdot 4 \ell^{2} \cdot \mu
$$

Pola resonansi berikutnya adalah nada atasnya yang merupakan frekuensi alaminya. Untuk frekuensi harmonik ke- $n$ ditentukan sebagai,

$$
f_{n}=(n+1) f_{0}=(n+1) \frac{v}{2 \ell}
$$

dengan $n=0,1,2$,...deretan harmonik, sehingga perbandingan frekuensi tersebut merupakan kelipatan bulat dari frekuensi nada dasarnya[16]. Berdasarkan Hukum Marsenne, hubungan frekuensi dasar pada dawai/senar yang kedua ujungnya terikat adalah [18],[15].

a. Berbanding terbalik dengan panjang senar.

b. Berbanding lurus dengan akar dari gaya tegangan senar.

c. Berbanding terbalik dengan akar dari massa jenis bahan senar.

\section{Nada dan Harmonik}

Nada adalah bunyi tunggal yang berasal dari sumber bunyi yang mempunyai ferkuensi tetap[19]. Contoh karakteristik bunyi adalah warna bunyi (timbre) ditunjukkan oleh komponen harmoniknya[9],[16]. Bentuk sinyal gelombang bunyi dapat dianalisis menurut harmonik-harmonik yang menyusunnya, disebut analisis harmonik atau juga disebut analisis Fourier yang secara matematika menganalisis fungsi-fungsi periodik[16]. Salah satu algoritmanya dikenal dengan Fast Fourier Transform (FFT) yaitu algoritma yang cepat untuk menganalisis sinyal dari domain waktu menjadi domain frekuensi. Penyelesaian algoritma FFT dapat dengan mudah dijalankan dalam program Excel dan Matlab.

Tangga nada diatonik didasarkan pada not-not angka, juga diberi nama dengan huruf abjad C-D-E-F-GA-B-C'[13]. Seiring perkembangan peradaban, lima nada lagi ditambahkan pada skala musik dunia barat yaitu nada tengahan cis (des), dis (eis), fis (ges), gis (as), ais (bes), sehingga keduabelas skala nada ini

\begin{tabular}{|c|c|c|c|c|c|}
\hline $\begin{array}{l}\text { Not } \\
\text { Nada }\end{array}$ & $\begin{array}{l}\text { Bunyi } \\
\text { Nada }\end{array}$ & $\begin{array}{c}\text { Tangga } \\
\text { Nada }\end{array}$ & $\begin{array}{c}\text { Frek. } \\
(\text { Hz) }\end{array}$ & Interval & $\begin{array}{l}\text { Jarak } \\
\text { Nada }\end{array}$ \\
\hline \multirow[t]{2}{*}{1} & do & $\mathrm{C}$ & 262 & Prime & \\
\hline & & $\mathrm{C}^{\#}$ atau $\mathrm{D}^{\mathrm{b}}$ & 277 & & 1 \\
\hline \multirow[t]{2}{*}{2} & re & D & 294 & Sekonde & \\
\hline & & $\mathrm{D}^{\#}$ atau $\mathrm{E}^{\mathrm{b}}$ & 311 & & 1 \\
\hline 3 & mi & $\mathbf{E}$ & 330 & Ters & \\
\hline \multirow[t]{2}{*}{4} & fa & $\mathbf{F}$ & 349 & Kwart & $1 / 2$ \\
\hline & & $F^{\#}$ atau $G^{b}$ & 370 & & 1 \\
\hline \multirow[t]{2}{*}{5} & sol & G & 392 & Kwin & \\
\hline & & $\mathrm{G}^{\#}$ atau $\mathrm{A}^{\mathrm{b}}$ & 415 & & 1 \\
\hline \multirow[t]{2}{*}{6} & La & A & 440 & Sext & \\
\hline & & $\mathrm{A}^{\#}$ atau $\mathrm{B}^{\mathrm{b}}$ & 466 & & 1 \\
\hline 7 & $\mathbf{s i}$ & B & 494 & Septime & \\
\hline 8 & Do' & $\mathbf{C}^{\prime}$ & 524 & Oktaf & $1 / 2$ \\
\hline
\end{tabular}
disebut skala Chromatic[4]. Frekuensi not-not skala kromatik dengan kenyaringan yang sama pada tangga nada standar (middle) diberikan pada Tabel 1 [11], [13].

Tabel 1. Skala kromatik dengan kenyaringan yang sama untuk satu oktaf. 


\section{METODE PENELITIAN}

Dalam melakukan penelitian ini bahan dan alat eksperimen yang dibutuhkan diantaranya: mistar, jangka sorong, neraca, mikrofon, smartphone yang berbasis android, komputer, perangkat lunak Cool edit Pro/Adobe Audition, Sound meter, dan alat musik gambo.

Pengumpulan data melalui studi pustaka dan studi kasus pada fenomena bunyi gambo. Unsur-unsur filosofis non sains ditelaah berdasarkan wawancara, observasi, dan kajian pustaka. Penentuan karakteristik sinyal bunyi gambo (seperti warna bunyi/timbre, frekuensi harmonik, frekuensi nada pelarasan, dan durasi) digunakan software cool edit pro/Adobe Audition dan Matlab, sedangkan intensitas bunyi nada menggunakan applikasi smartphone android. Kelajuan perambatan bunyi pada masing-masing dawai gambo dianalisis berdasarkan formula teoritis dan fitting grafik. Data-data yang diperoleh dianalisis secara deskriptif kuantitatif untuk menentukan besaran fisis yang terkait dengan karakteristik akustik gambo.

\section{HASIL DAN PEMBAHASAN}

\section{Ukuran dan Makna Filosofis Gambo}

Dole Mose, Fuadi, dan Abdullah Z, mengatakan bahwa untuk ukuran gambo di berbagai daerah Mbojo belum diketahui ukuran bakunya, hal ini dikarenakan dalam pembuatanya lebih kepada rasa dan kesesuaian jiwa sang pembuat atau pemain saja, namun dari beberapa gambo yang diobservasi diperoleh data bagianbagian dan spesifikasi ukurannya ditunjukkan dalam Gambar 1.

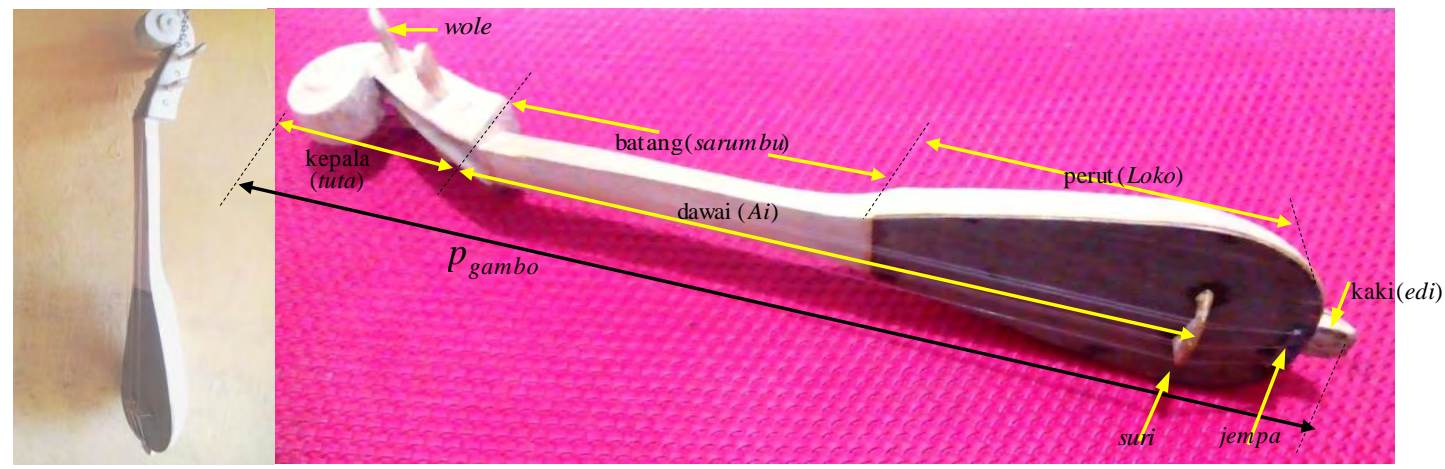

Gambar 1. Bagian-bagian alat musik Gambo Mbojo (sumber: koleksi pribadi).

Gambo terdiri dari empat bagian utama yang bersimbolkan struktur tubuh manusia yaitu: bagian tuta (kepala), bagian sarumbu (batang), bagian loko (perut), dan bagian edi (kaki), ditunjukkan dalam Tabel 2 berikut.

Tabel 2. Hasil analisis ukuran dan bagian-bagian Gambo

\begin{tabular}{|c|c|c|c|}
\hline No & $\begin{array}{r}\text { Bagian } \\
\text { Gambo } \\
\end{array}$ & $\begin{array}{c}\begin{array}{c}\text { Ukuran } \\
(\mathbf{c m})\end{array} \\
\end{array}$ & Keterangan \\
\hline 1 & $\begin{array}{l}\text { Bagian Tuta } \\
\text { (kepala) }\end{array}$ & $\begin{array}{ll}\text { a. } & P_{\text {tuta }}=14-17 \\
\text { b. } & L_{\text {tuta }}=3,5-7,5 \\
\text { c. } & P_{\text {wole }}=5,5 ; 6 ; 6,3 ; 6,5 ; 7\end{array}$ & $\begin{array}{l}\text { pada bagian kepala terdapat } 5 \text { atau } 6 \text { buah putaran } \\
\text { dawai yaitu alat penyetem/pelarasan dawai yang } \\
\text { disebut "Wole". Kepala dan batang menyambung. }\end{array}$ \\
\hline 2 & $\begin{array}{l}\text { Bagian sarumbu } \\
\text { (batang/gagang) }\end{array}$ & $\begin{array}{ll}\text { a. } & P_{\text {sarumbu }}=22,5 \\
\text { b. } & L_{\text {sarumbu }} \\
& =2,6 \text { (ganjal senar atas) } \\
& =3,5-4,5 \text { (pangkal perut). }\end{array}$ & $\begin{array}{l}\text { Gambo tidak mempergunakan garis pembatas nada } \\
\text { (frets) seperti pada alat musik gitar, sehingga } \\
\text { kemampuan mengolah rasa musikal yang tinggi } \\
\text { dalam memainkan gambo menjadi kunci yang } \\
\text { sangat penting. }\end{array}$ \\
\hline
\end{tabular}


Tabel 2. (Lanjutan) Hasil analisis ukuran dan bagian-bagian Gambo

\begin{tabular}{llll}
\hline No & $\begin{array}{l}\text { Bagian } \\
\text { Gambo }\end{array}$ & & \multicolumn{1}{c}{$\begin{array}{c}\text { Ukuran } \\
(\mathbf{c m})\end{array}$} \\
\hline \hline 3 & Bagian loko & a. & $P_{\text {loko }}=23,5$ \\
& (perut) & b. & $L_{\text {loko }}=12-13$ (paling lebar), \\
& & & $L_{\text {loko }}=9,5$ (bagian tengah), \\
& & & $L_{l o k o}=4,5-5,5$ (bagian pangkal), \\
& & c. & $t_{\text {loko }}=4$
\end{tabular}

Bagian yang gembung disebut "Perut". Torehan dari sebelah depan yang rata sampai menyerupai mangkok dengan ketipisan dindingnya sekiar $3 / 4 \mathrm{~cm}$ $(0,7 \mathrm{~mm})$. Pada bagian perut terdapat "kenta" atau membran dibuat dari kulit kambing dengan maksud agar udara di dalam perut berfungsi sebagai resonator (wadah gema) yang memperkuat dan memberi warna yang khas pada bunyi gambo. Sisi pinggir kulit membran ini dipaku dengan lapisan rotan dengan rapi, rapat, dan kencang pada bibir "mangkok" nya sebelah luar sebagai penguat/penjepit, tetapi jika menggunakan tripleks atau logam penutup panci maka cukup dilem atau dipaku.

Di atas membran ada bagian yang menahan ketegangan dawai yaitu "suri/tuki" (pengganjal) berfungsi sebagai penyekat antara senar dan membran kulit.

\begin{tabular}{|c|c|c|c|}
\hline 4 & $\begin{array}{l}\text { Bagian edi } \\
\text { (kaki). }\end{array}$ & $\begin{array}{ll}\text { a. } & P_{\text {edi }}=2,7 \\
\text { b. } & L_{\text {edi }}=2,5 \\
\text { c. } & P_{\text {jempa }}=\left(1,3+0,7_{\text {terlipat ke bawah }}\right) \\
\text { d. } & L_{\text {jempa }}=\left(3,3-2,5_{\text {kerucut ke bawah }}\right)\end{array}$ & $\begin{array}{l}\text { Benda yang terpasang paling bawah dari badan } \\
\text { gambo yaitu pada pangkal bagian kaki terdapat } \\
\text { "Jempa" yaitu tempat berkaitnya dawai. }\end{array}$ \\
\hline 5 & $\begin{array}{l}\text { Suri/tuki (ganjal } \\
\text { senar bawah/ } \\
\text { bridge). }\end{array}$ & $\begin{array}{rlr}\text { a. } & P_{\text {suri }} & =4 \text { (pangkal atas) } \\
& =5 \text { (pangkal bawah) } \\
\text { b. } & L_{\text {suri }} & =0,04 \\
\text { c. } & t_{\text {suri }} & =1,5_{+1,7}\end{array}$ & $\begin{array}{l}\text { Suri dibuat sedikit melengkung agar dawai dapat } \\
\text { dipetik dengan baik, ketinggian lengkungan sisi } \\
\text { tengah kira-kira } 1,7 \mathrm{~cm} \text { sedangkan bagian pinggir } \\
\text { sebesar } 1,5 \mathrm{~cm} \text { dari bidang membran. }\end{array}$ \\
\hline 6 & $A i$ (dawai). & $\begin{array}{ll}\text { a. } & P_{a i}=39,3-51 \\
\text { b. } & x_{a i}=0,1-1,5 \\
\text { c. } & d_{a i-1}=0,55 \mathrm{~mm} \\
& \mu_{a i-1}=30,05 \times 10^{-5} \mathrm{~kg} / \mathrm{m} . \\
\text { d. } & d_{a i-2}=0,64 \mathrm{~mm} ; \\
& \mu_{a i-2}=38,13 \times 10^{-5} \mathrm{~kg} / \mathrm{m} . \\
\text { e. } & d_{a i-3}=0,78 \mathrm{~mm} ; \\
& \mu_{a i-3}=48,44 \times 10^{-5} \mathrm{~kg} / \mathrm{m} .\end{array}$ & $\begin{array}{l}\text { Gambo memiliki } 2 \text { atau } 3 \text { pasang dawai dengan } \\
\text { kata lain hanya ada antara } 5 \text { atau } 6 \text { saja yang } \\
\text { disusun dalam } 3 \text { susunan nada laras, hal ini bagi } \\
\text { masyarakat Mbojo dikaitkan dengan } 6 \text { perkara } \\
\text { rukun Iman dan } 5 \text { perkara rukun Islam serta angka } \\
3 \text { merupakan jumlah minimal yang dilakukan umat } \\
\text { islam mengulang dalam berdoa. Dawai gambo } \\
\text { disebut "ai gambo" yaitu dawai dari plastik/nilon } \\
\text { untuk pancingan ikan. Ai gambo merupakan salah } \\
\text { satu bagian penting pada sistem gambo karena } \\
\text { merupakan sumber bunyi yang memiliki ukuran } \\
\text { diameter atau kerapatan tertentu. Diantara ketiga } \\
\text { dawai dipasang dengan jarak pisah } \pm 1,5 \text { cm, dan } \\
\text { senar berpasangan dipasang pada jarak pisah } \pm 0,1 \\
\text { cm. Dawai yang berpasangan dimaksudkan untuk } \\
\text { membentuk efek bunyi, etnis setempat } \\
\text { menyebutnya"Kapantu eli". }\end{array}$ \\
\hline 7 & Woke (pusar) & a. $\quad d_{\text {hole }}=1,4$ & $\begin{array}{l}\text { Woke (pusar) yaitu lubang bunyi berada di } \\
\text { belakang dinding perut gambo agar udara dalam } \\
\text { perut gambus dapat bergetar bebas tanpa } \\
\text { mengalami halangan. }\end{array}$ \\
\hline 8 & $p_{\text {gambo }}$ & a. $\quad 62,7$ & $\begin{array}{l}\text { Panjang gambo merupakan panjang keseluruhan } \\
\text { mulai dari ujung kepala hingga ujung kaki yaitu }= \\
P_{\text {tuta }}+P_{\text {sarumbu }}+P_{\text {loko }}+P_{\text {edi }} \text {. }\end{array}$ \\
\hline
\end{tabular}


Bahan dasar Gambo dibuat dari kayu Nara, menurut orang Bima (etnis Mbojo) sejenis kayu Sonokeling berwarna kuning[6], atau jenis kayu yang lain adalah kayu Nangka dan kayu Rida. Menurut pembuatnya (Dole Mose, 2015) bahan terbaik untuk alat musik Gambo adalah menggunakan kayu Nangka karena kayu jenis ini memiliki serat yang rapat, mudah diolah/dipahat/dibentuk, ringan, dan tidak mudah retak, serta mampu menjadi dinding pemantul bunyi yang baik.

Proses pembuatan Gambo tidak memerlukan bahan-bahan yang terpisah atau batang kayu yang dipasang atau digabung-gabungkan menjadi satu melainkan dibuat dari satu kayu utuh yang langsung dibentuk menjadi Gambo, kecuali asesorisnya. Proses pembuatan gambo dapat dilakukan dalam berbagai tahap mulai dari memilih bahan utama/dasar kayu hingga proses-proses teknis yang semuanya menggunakan cara-cara konvensional. Namun secara umum prinsip yang harus dilakukan adalah selalu mengutamakan kelestarian lingkungan hingga dalam prosesnya selalu diawali dengan melafazkan kalimat "Basmallah" dengan niat yang baik dan ikhlas untuk dipergunakan sebagai sesuatu untuk kebaikan, karena jika tidak dilakukan sesuai syariat tersebut para pembuat akan mengalami kesulitan dan kesalahan-kesalahan dalam mekonstruksi alat musik gambo tersebut, alat musik akan mudah terjadi keretakan, bahkan aura ketika memainkan alat musik tersebut tidak akan keluar sehingga para penonton akan merasa tidak nyaman dan kurang dapat menikmati alunan musik yang dihasilkan gambo tersebut, hal ini telah banyak dialami oleh para pelaku musik gambo di daerah Bima dan Dompu. Selain dari segi kwalitas, pembuat pun akan terkena gangguan kesehatan.

\section{Telaah Fisis Alat Musik Gambo}

Untuk memperoleh informasi fisis terkait bunyi alat musik gambo, dilakukan beberapa telaah melalui eksperimen, diantaranya:

1. Penentuan besaran fisis masing-masing senar Gambo pada pelarasan standar.

Hasil analisis frekuensi harmonik, gaya tegang senar, dan kelajuan perambatan bunyi pada keadaan tunning/pelarasan standar untuk masing-masing dawai, ditunjukkan dalam Tabel 3.

Tabel 3. Karakteristik fisis masing-masing senar Gambo pada keadaan pelarasan standar.

\begin{tabular}{|c|c|c|c|c|c|c|c|c|c|}
\hline \multirow{2}{*}{ Dawai } & \multirow{2}{*}{$\begin{array}{l}\mu(\mathrm{kg} / \mathrm{m}) \\
\left(\times 10^{-5}\right)\end{array}$} & \multirow{2}{*}{$\begin{array}{c}\boldsymbol{L} \\
(\mathrm{m})\end{array}$} & \multicolumn{4}{|c|}{ Frek. Harmonik, $f_{n=0,1,2,3,(\mathrm{~Hz})}$} & \multirow{2}{*}{$\begin{array}{l}\text { Deret } \\
\text { Nada }\end{array}$} & \multirow{2}{*}{$\begin{array}{c}v \\
(\mathbf{m} / \mathbf{s})\end{array}$} & \multirow{2}{*}{$\begin{array}{c}F \\
(\mathbf{N})\end{array}$} \\
\hline & & & 0 & 1 & 2 & 3 & & & \\
\hline $\mathrm{I}$ & 30.06 & 0.393 & 391.80 & 785.20 & 1173.81 & 1565.14 & $\mathrm{G}_{4}$ & 307.95 & 45.60 \\
\hline II & 38.13 & \pm & 263.40 & 523.29 & 785.60 & 1045.00 & $\mathrm{C}_{4}$ & 205.77 & 25.40 \\
\hline III & 48.44 & 0.001 & 174.30 & 348.18 & 524.45 & 695.63 & $\mathrm{~F}_{3}$ & 137.00 & 14.30 \\
\hline
\end{tabular}

Berdasarkan data frekuensi dasar yang diperoleh, bahwa nilai frekuensi 391,80; 263,40; dan 174,30 adalah identik dengan nilai frekuensi dari sistem tangga nada dalam teori musik internasional yaitu $\mathrm{G}_{4-392}$; $\mathrm{C}_{4-262} ; \mathrm{F}_{3-174,61}$. Berdasarkan hasil ini maka dapat dinyatakan bahwa pelarasan nada pada alat musik gambo di masyarakat etnis Mbojo adalah pada nada G, C, F atau dengan bunyi nada sol, do, fa (untuk nada dasar do = C) atau dikenal dalam istilah kwart [6].

Setelan/pelarasan nada dasar pada setiap "Ai gambo" pada prinsipnya tidak menggunakan pembakuan seperti pada alat-alat musik modern, tetapi mengacu atau menyesuaikan dengan feel musical/comon sense dari penyanyi dan pemainya saja, namun meski demikian secara analisis sederhana dari 3 orang pemain gambo yang diwawancara tidak terdengar perbedaan yang signifikan dalam pengaturan nada dasar (nada pelarasan masing-masing dawai/ai), oleh karena itu perlu untuk diketahui dan ditetapkan nada standar yang lazim digunakan, sebab masyarakat setempat mengenal bahwa ketika dawai disetel dengan standar yang lain akan terasa lebih kencang atau lebih kendor sehingga mempengaruhi bunyi dan kualitas memainkannya, demikian pula ukuran panjang dawainya, hal ini terkait dengan ukuran Gambo yang dibuat. Jika ukuran gambo terlalu besar atau kecil dari yang lazimnya maka akan mempengaruhi jarakjarak nada pada saat petikan/memainkannya.

Hubungan frekuensi dasar dengan panjang dawai yang bergetar, dapat dinyatakan dengan persamaan (1) [16], sehingga besarnya kelajuan perambatan gelombang bunyi pada masing masing dawai gambo (aigambo) dapat dihitung dengan persamaan (2) dan besarnya ketegangan dawai ditentukan oleh persamaan (3). Di sisi lain hubungan perubahan setiap panjang dawai gambo terhadap frekuensi dasar dapat dicontohkan dalam Gambar 2. Gambaran suatu hubungan antara frekuensi dasar dan perubahan panjang dawai yang diatur setiap $1 \mathrm{~cm}$ untuk dawai nomor 3 menghasilkan pola grafik hubungan pangkat (power). Sementara itu, adapun nada-nada yang diperoleh dalam petikan gambo ditunjukkan dalam Tabel 4. 


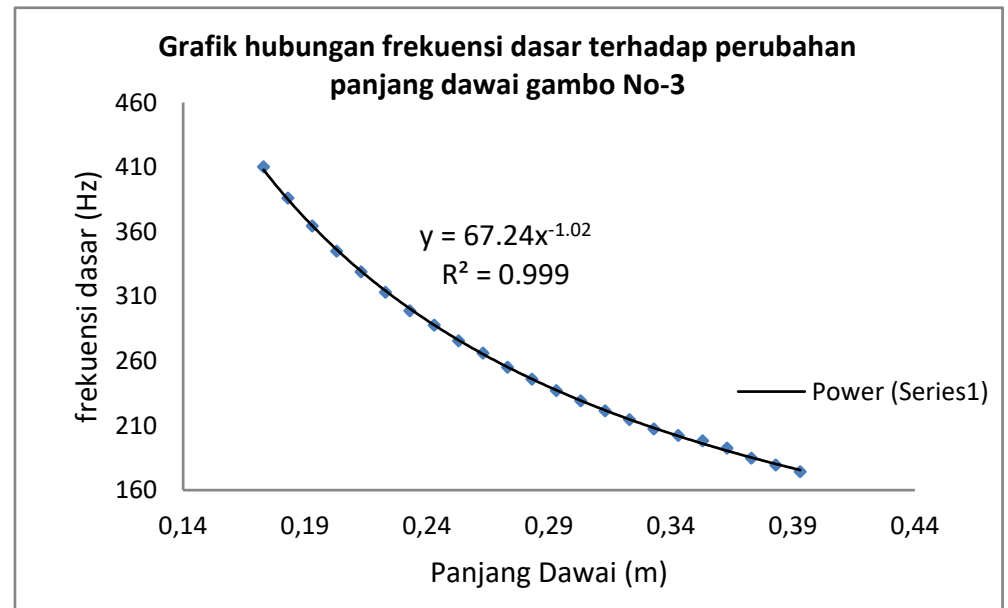

Gambar 2. Pola hubungan frekuensi dasar dan panjang getaran dawai gambo nomor 3.

Berdasarkan analisis grafik dihasilkan suatu persamaan matematis yang berkaitan dengan bunyi nadanada dasar pada alat musik gambo untuk masing-masing dawai secara berturut-turut $f_{0-I}=152,1 . L^{-1.02}$, $f_{0-I I}=101,2 \cdot L^{-1.02}$, dan $f_{0-I I I}=67,24 \cdot L^{-1.02}$ yang secara umum menggambarkan hubungan $f_{0}(L)=A L^{B}$, diperoleh $A_{I}=152,1 ; A_{I I}=101,2 ;$ dan $A_{I I I}=67,24$ serta rata-rata $\left(B_{I, I I, I I I}\right)=-1,02$ sesuai dengan teori karena mendekati $-1,\left(f_{0}=\frac{v}{2} \ell^{-1}\right)[3]$. Nilai $A$ dapat digunakan untuk menentukan kelajuan perambatan gelombang dimana berdasarkan hubungan untuk keadaan dasar yaitu $(v=2 A)$ sehingga diperoleh besarnya kelajuan perambatan bunyi pada masing-masing dawai gambo berturut-turut adalah $(304,2$; $202,4 ; 134,4) \mathrm{m} / \mathrm{s}$, atau besar kesalahan relatif jika dibandingkan dengan nilai kelajuan bunyi yang diperoleh dengan metode perhitungan langsung hanya $1,22 \% ; 1,64 \%$; dan 1,90\% (namun akan lebih teliti jika menggunakan metode grafik karena melibatkan kelompok data yang banyak). Persamaan ini juga dapat difungsikan untuk menentukan nilai frekuensi dasar dari nada pada octav yang lebih rendah atau yang lebih tinggi. Aktivitas ini dalam pembelajaran fisika akan dapat mengatasi kelemahan konsep siswa yang menghubungkan kelajuan perambatan bunyi pada dawai terhadap frekuensi dan panjang gelombang yang masih sering ditemui[7].

Tabel 4. Data komponen nada dasar (not-not nada) yang dominan dimainkan pada alat musik gambo dalam mengiringi lagu-lagu daerah Mbojo dan jenis tangga nadanya.

\begin{tabular}{|c|c|c|c|c|c|c|c|c|c|}
\hline \multicolumn{3}{|c|}{ Jenis Dawai Gambo } & \multirow{2}{*}{\multicolumn{2}{|c|}{$\begin{array}{c}\text { Panjang dawai } \\
\text { getar }(\mathbf{m}) \\
L_{0}(\exp ) \\
\end{array}$}} & \multirow{2}{*}{$\begin{array}{c}\text { Panjang } \\
\text { gelombang (m) } \\
\lambda_{0(\exp )} \\
\end{array}$} & \multicolumn{2}{|c|}{$\begin{array}{c}\text { frekuensi dasar } \\
\text { nada }(\mathrm{Hz})\end{array}$} & \multirow{2}{*}{$\begin{array}{l}\text { tangga } \\
\text { nada }\end{array}$} & \multirow{2}{*}{$\begin{array}{l}\text { Bunyi } \\
\text { Nada }\end{array}$} \\
\hline & & & & & & $f_{0}$ (eksp) & $f_{0}$ (teori) & & \\
\hline \multirow{2}{*}{\multicolumn{3}{|c|}{$\begin{array}{l}\text { Dawai-1 } \\
\text { Nada dasar do }=G_{4}\end{array}$}} & 1 & 0.392 & 0,780 & 391.80 & 392.00 & $\mathbf{G}_{4}$ & do \\
\hline & & & 2 & 0.376 & 0,740 & 417.10 & 415.30 & $\mathbf{G}^{\#}{ }_{4} / \mathbf{A}^{\mathbf{b}_{4}}$ & \\
\hline \multirow[t]{4}{*}{ dik: $\quad L_{0}=$} & 0.392 & M & 3 & - & - & - & 440.00 & $\mathrm{~A}_{4}$ & re \\
\hline & 392.000 & $\mathrm{~Hz}$ & 4 & 0.337 & 0,660 & 464.21 & 466.16 & $\mathbf{A}^{\#}{ }_{4} / \mathbf{B}^{b_{4}}$ & \\
\hline & 153.660 & Hz.m & 5 & - & - & - & 493.88 & $\mathrm{~B}_{4}$ & $\mathrm{Mi}$ \\
\hline & & & 6 & 0.300 & 0,590 & 525.23 & 523.25 & $\mathrm{C}_{5}$ & $\mathrm{Fa}$ \\
\hline \multirow{2}{*}{\multicolumn{3}{|c|}{$\begin{array}{l}\text { Dawai-2 } \\
\text { Nada dasar do }=\mathrm{C}_{4}\end{array}$}} & 1 & 0.392 & 0,784 & 263.40 & 261.80 & $\mathrm{C}_{4}$ & Do \\
\hline & & & 2 & 0.376 & 0,752 & 279.13 & 277.18 & $\mathbf{C}^{\#}{ }_{4} / \mathbf{D}^{\mathbf{b}_{4}}$ & \\
\hline \multirow[t]{4}{*}{ dik: $\quad L_{0}=$} & 0.392 & $\mathrm{~m}$ & 3 & - & - & - & 293.66 & $\mathrm{D}_{4}$ & $\operatorname{Re}$ \\
\hline & 261.80 & $\mathrm{~Hz}$ & 4 & 0.337 & 0,672 & 309.53 & 311.13 & $\mathbf{D}^{\#}{ }_{4} / \mathbf{E}^{\mathbf{b}_{4}}$ & \\
\hline & 102.63 & Hz.m & 5 & - & - & - & 329.63 & $\mathrm{E}_{4}$ & $\mathrm{Mi}$ \\
\hline & & & 6 & 0.290 & 0,600 & 347.24 & 349.23 & $\mathbf{F}_{4}$ & $\mathrm{Fa}$ \\
\hline \multirow{2}{*}{\multicolumn{3}{|c|}{$\begin{array}{l}\text { Dawai-3 } \\
\text { Nada dasar do }=F_{3}\end{array}$}} & 1 & 0.392 & 0,784 & 174.30 & 174.61 & $\mathbf{F}_{3}$ & Do \\
\hline & & & 2 & 0.375 & 0,750 & 183.89 & 185.00 & $\mathbf{F}^{\#}{ }_{3} / \mathbf{G}^{\mathbf{b}_{3}}$ & \\
\hline \multirow{4}{*}{ dik: $\quad L_{0}=$} & 0.392 & $\mathrm{~m}$ & 3 & - & - & - & - & $\mathrm{G}_{3}$ & $\mathrm{Re}$ \\
\hline & 174.30 & $\mathrm{~Hz}$ & 4 & 0.337 & 0,674 & 208.21 & 207.65 & $\mathbf{G}^{\#}{ }_{3} / \mathbf{A}^{\mathbf{b}_{3}}$ & \\
\hline & 68.33 & Hz.m & 5 & - & - & - & - & $\mathrm{A}_{3}$ & $\mathrm{Mi}$ \\
\hline & & & 6 & 0.300 & 0,600 & 234.26 & 233.08 & $\mathbf{A}^{\#}{ }_{3} / \mathbf{B}^{\mathbf{b}} \mathbf{3}_{3}$ & $\mathrm{Fa}$ \\
\hline
\end{tabular}


Berdasarkan tabel 4 di atas, nada-nada yang diperoleh dalam petikan gambo didominasi hanya dibunyikan 4 nada saja, yang diperoleh berdasarkan posisi dan ukuran dawai yang dipetik/bergetar pada masingmasing dawai dengan menekan dawai pada posisi tertentu. Sebagai contoh pada Dawai-1 deretan nada yang dimainkan pada dawai tersebut hanya pada nada $\mathbf{G}_{\mathbf{4}}, \mathbf{G}_{\mathbf{4}} \mathbf{4} / \mathbf{A}_{\mathbf{4}}^{\mathbf{b}}, \mathbf{A}_{\mathbf{4}} / \mathbf{B}^{\mathbf{b}}$, dan $\mathbf{C}_{\mathbf{5}}$. Jika dikaitkan dengan skala nada internasional skala nada gambo masuk dalam daftar tersebut, namun deretan tangga nada pada alat musik gambo tidak mengikuti jenis tangga nada kromatik maupun diatonis, dan jenis tangga nada pada seluruh alat musik tradisional etnik Mbojo khususnya Gambo belum memiliki atau ditetapkan istilahnya seperti halnya nama tangga nada alat musik tradisional Jawa dan Sunda.

2. Analisis Fourier dalam penentuan karakteristik bentuk (waveform) gelombang bunyi nada Gambo. Hasil analisis bunyi nada pelarasan gambo yang dicuplik dengan software Adobe Audition dan FFT Matlab diperoleh contoh pola sinyal gelombang yang ditunjukkan dalam Gambar 3.
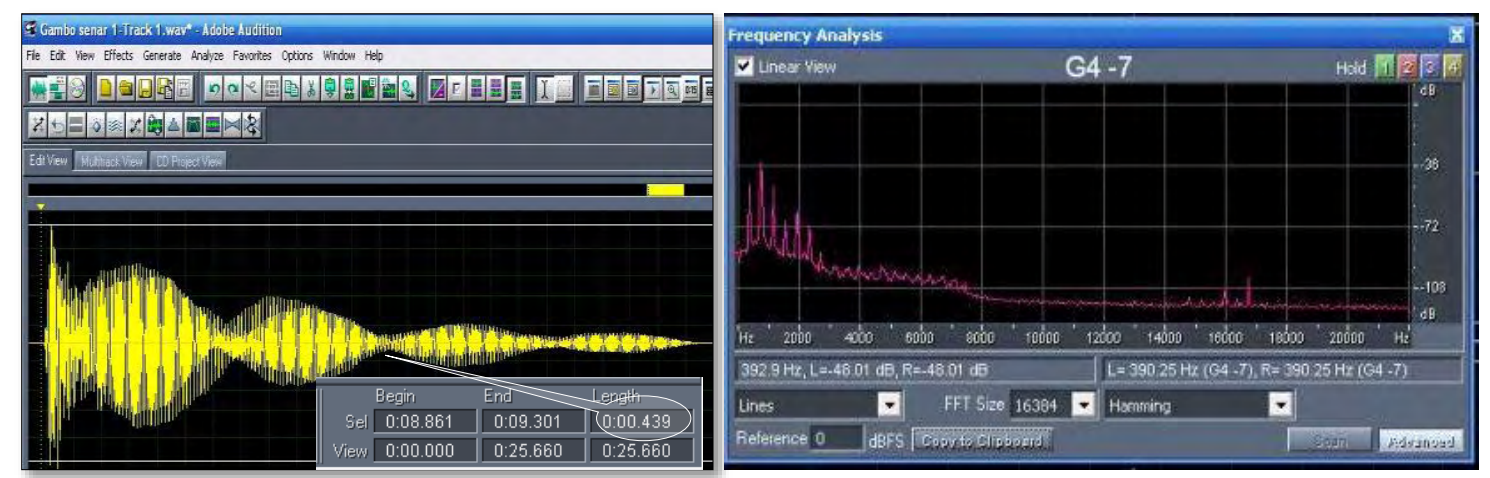

Gambar 3a. Pola sinyal bunyi nada laras pada dawai-1, durasi bunyi, dan spektrum frekuensi.

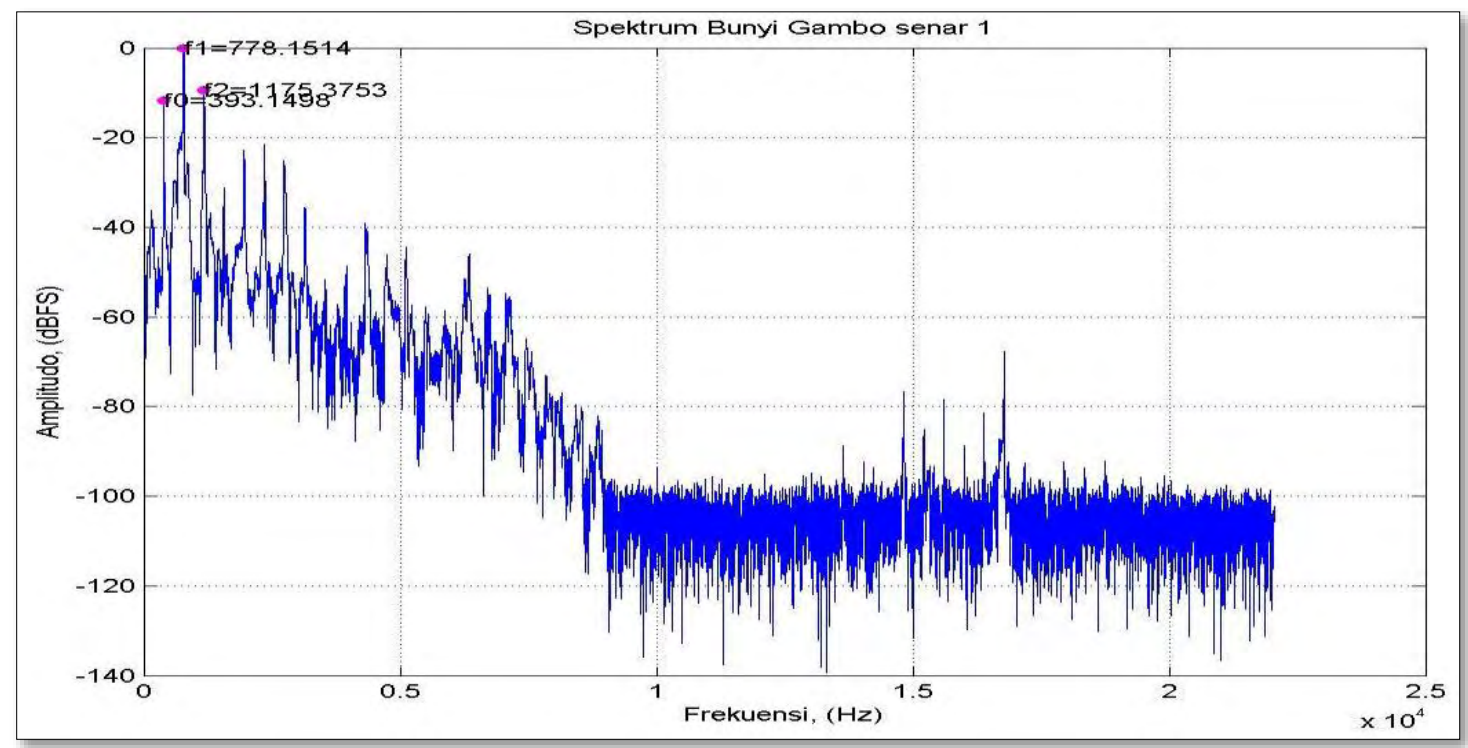

Gambar 3b. (Lanjutan) Pola sinyal bunyi nada laras pada dawai-1, durasi bunyi, dan spektrum frekuensi.

Berdasarkan bentuk pola gelombang yang terlihat pada Gambar 3, menunjukkan adanya warna bunyi (Timbre) tertentu, dimana berkaitan dengan jumlah kandungan harmoniknya. Sinyal yang terbentuk juga terlihat adanya pola pelayangan dan redaman. Terbentuknya pelayangan disebabkan karena pada dawai1 disusun dalam dua dawai disetel identik yang bagi masyarakat setempat dimaksudkan untuk menghasilkan efek bunyi "kapantu eli" yang dalam konteks pembelajaran fisika dikenal sebagai pelayangan bunyi. Ini merupakan salah satu cara memperoleh gambaran visual tentang karakteristik bunyi alat musik Gambo yang dapat digunakan sebagai bahan pembelajaran konsep pelayangan (beat) dan redaman, sedangkan Adobe Audition dapat digunakan dalam pembelajaran fisika karena dapat merekam sinyal suara, memiliki fasilitas analisis transformasi Fourier, sehingga dapat menampilkan dan mengukur spektrum frekuensi warna bunyi secara visual dan numerik. 
3. Intensitas gelombang bunyi nada gambo.

Penentuan besarnya intensitas bunyi nada gambo dilakukan dengan perangkat lunak "sound meter" applikasi dari smartphone android. Hasil yang diperoleh menunjukkan intensitas rata-rata sebesar $(88,07$ $\pm 0,20) \mathrm{dB}$.

Berdasarkan analisis yang telah dilakukan, kegiatan pembelajaran fisika yang dapat diterapkan melalui alat musik gambo diantaranya menggali dan merekonstruksi terkait konsep getaran dan bunyi, diantaranya: Ukuran dan jenis dawai yang digunakan serta pengaruhnya terhadap bunyi (sifat bahan: kerapatannya), Warna bunyi/timbre (terkait pada pola atau bentuk sinyal gelombang yang terlihat pada layar Osciloscop), Durasi perekaman bunyi untuk setiap nada yang dihasilkan oleh gambo, Besarnya frekuensi dasar masingmasing dawai pada pelarasan/tunning standar, dan kaitannya dengan nada dalam teori musik internasional, Kandungan frekuensi-frekuensi harmonik dari bunyi nada yang dihasilkan dawai gambo, Kelajuan perambatan gelombang bunyi pada masing-masing dawai, Besarnya ketegangan masing-masing dawai pada saat pelarasan/tunning standar, Intensitas bunyi, konsep pelayangan bunyi, Frekuensi dasar nada-nada (atau not-not nada) yang dominan dimainkan pada alat musik gambo dalam mengiringi lagu-lagu daerah Mbojo, dan menentukan jenis tangga nadanya, hingga mempelajari pola atau hubungan matematis anatara frekuensi dasar nada-nada terhadap perubahan panjang dawai.

\section{KESIMPULAN}

Berdasarkan uraian hasil penelitian di atas, dapat disimpulkan bahwa informasi filosofis, fisis dan matematis alat musik gambo yang ditentukan melalui rancangan eksperimen terintegrasi ICT berbasis smartphone dan komputer dapat dimanfaatkan sebagai alternatif media pembelajaran fisika yang dapat memberikan kontribusi dalam mengatasi dan meningkatkan penguasaan konsep fisika siswa dan membentuk generasi yang berkarakter budaya.

\section{UCAPAN TERIMA KASIH}

Penulis mengucapkan terima kasih kepada berbagai pihak yang telah membantu dalam penulisan makalah ini, khususnya sanggar seni Paju Monca Kota Bima dalam menyediakan fasilitas terkait alat-alat musik tradisional Mbojo.

\section{REFERENSI}

1. A. Malingi, Mengenal Alat Musik Tradisional Bima-Dompu, Mahani Persada, Mataram (2010).

2. Adobe ${ }^{\circledR}$ Audition ${ }^{\mathrm{TM}}$ 1.5, Adobe Systems Incorporated, All rights reserved, (2004).

3. C. LoPresto, Experimenting with Guitar Strings. The Physics Teacher of Journal, vol.44. N0. 509, November (2006).

4. C. M. Presto, Experimenting with Brass Musical Instruments, http//www.iop.org/EJ/abstract/00319120/38/4/302 (2003).

5. D. Halliday, dan R. Resnick, Fisika Jilid 2, Erlangga, Jakarta (1997).

6. Departemen Pendidikan dan Kebudayaan Indonesia, Ensiklopedia Musik Indonesia, Seri F-G. Proyek Inventarisasi dan Dokumentasi Kebudayaan Daerah, Jakarta (1985).

7. Eshach, Haim, Development of a Student-centered to Asses Middle School Students Conceptual Understanding of Sound, the Physics Education Research of Journal, PACS.01.40.-d,43.10.Sv, 21 Januari (2014).

8. E. R. Huggins, Fourier Analysis in Introductory Physics. Website: http//www.lish.huggins@, Darthmouth.edu (2007).

9. E. Indra, Pelajaran IPA Fisika, Yrama Widya, Bandung (2007).

10. F. W. Sears, (ed), Fisika Universitas Edisi Kesepuluh Jilid 2. Erlangga, Jakarta (2001).

11. Giancoli, Fisika Edisi Kelima Jilid 1, Erlangga, Jakarta (1998).

12. J. Groppe, The Hope of Audacity (to Teach Acoustics). The Physics Teacher. American Association of Physics Teacher, (2011).

13. M. Widagdo, Buku Pelajaran Fisika Jilid 2, Erlangga, Jakarta (1984).

14. M. A. Ahmad, Sejarah \& Pengembangan Sistem Operasi Android, http://bebmen.com/5114/mengenalsistem-operasi-android.html, (2013). 


\section{PROSIDING SNIPS $2016 \quad$ RP 2 SNIPS}

15. Nelkon (ed), Advanced Level Physics, Third edition with SI units. Heinem Education Book, Ltd (1975).

16. P. A. Tipler, Fisika untuk Sains dan Teknik Jilid 1, Erlangga, Jakarta (2001).

17. Sears, Soedarjana, Mekanika Panas Bunyi, Diwantara, Bandung (1963).

18. Sutrisno, Seri Fisika Dasar Gelombang dan Optik, ITB, Bandung (1979).

19. Sulistyo, dan P. Setyono, Intisari Fisika, Pustaka Setia, Bandung (2003).

20. S. Pavel (ed), Asymptotic Solution for the Problem of Sound Propagation in a Sea with an Underwater Canyon. J. Accoust. Soc. Am. 136 (4), Pt.2 ,Oktober (2014).

21. O. Douglas, (ed), Four Free Software Package Related to the Physics of Sound. The Physics Teacher Journal, vol.51. Februari (2013). 